CLINICAL STUDY

\title{
A novel germline inactivating mutation in the CASR gene in an Italian kindred affected by familial hypocalciuric hypercalcemia
}

\author{
Alberto Falchetti, Alessia Gozzini, Annalisa Terranegra ${ }^{1}$, Laura Soldati ${ }^{2}$, Giuseppe Vezzoli ${ }^{1}$, Gigliola Leoncini, \\ Francesca Giusti, Francesco Franceschelli, Laura Masi, Annalisa Tanini, Loredana Cavalli and Maria Luisa Brandi \\ Unit of Metabolic Bone Diseases, Department of Internal Medicine, University of Florence, Viale Morgagni 85, 50135 Florence, Italy, ${ }^{1}$ Nephrology and \\ Dialysis Unit, Scientific Institute San Raffaele Hospital, Vita Salute University, Milan, Italy and ${ }^{2}$ Department of Medicine, Surgery and Dentistry, \\ Università degli Studi di Milano, Milan, Italy \\ (Correspondence should be addressed to M L Brandi; Email: m.brandi@dmi.unifi.it)
}

\begin{abstract}
Objective: Familial hypocalciuric hypercalcemia (FHH) syndrome is a rare benign condition, inherited as an autosomal dominant trait, in which inactivating mutations of the calcium-sensing receptor (CASR) gene affects the body's ability to regulate calcium homeostasis. Its outcome is featured by increased levels of serum calcium, moderate hypophosphatemia, and inadequately normal or elevated circulating parathyroid hormone levels. Affected patients are mostly asymptomatic and do not benefit from surgical resection of their mildly enlarged parathyroids.

Design: We evaluated for hypercalcemia an Italian family that was identified via a young adult male proband referred to our center for parathyroidectomy.

Methods: The patients and the family members were evaluated both biochemically and genetically as suspected FHH subjects. An in vitro functional study was performed by site-directed mutagenesis, and CASR activity was monitored by measuring intracellular calcium $\left(\left[\mathrm{Ca}^{2+}\right]_{\mathrm{i}}\right)$.

Results: The patient had a novel germline heterozygous CASR mutation (c.361_364GATT; p.D121del/fsX122). The mutation caused a premature stop codon at codon 122, exiting a truncated protein. The biochemical phenotype of all family members carrying the heterozygous deletion was concordant with classic FHH syndrome.

Conclusions: Our findings confirm the role of CASR gene mutational analysis to offer a valuable addition for the recognition of $\mathrm{FHH}$ in hypercalcemic patients not yet characterized for a positive familial history of hypercalcemia, the only condition that identifies CASR gene mutations in hypercalcemia.
\end{abstract}

European Journal of Endocrinology 166 933-940

\section{Introduction}

Familial hypocalciuric hypercalcemia (FHH) syndrome (OMIM \#145980) is a rare benign condition, inherited as an autosomal dominant trait, in which inactivating mutations of the calcium-sensing receptor (CASR) gene affect the body's ability to regulate calcium homeostasis (1). FHH is featured by increased levels of serum calcium, moderate hypophosphatemia, inadequately normal or elevated circulating parathyroid hormone (PTH) levels (when correlated with serum calcium levels) mildly elevated in $5-10 \%$ of cases, and a normal urinary calcium excretion (2). Consequently, FHH is clinically similar to sporadic, nonsyndromic, early diagnosed primary hyperparathyroidism (PHPT).

FHH patients are mostly asymptomatic and do not benefit from surgical resection of their mildly enlarged parathyroids as surgery cannot correct the genetically determined abnormal set-point of calciumdependent PTH secretion $(3,4)$. Both FHH-associated hypercalcemia and relative hypocalciuria (urinary calcium/creatinine clearance ratio typically $<0.01$ ) are lifelong highly penetrant due to inactivation of CASR protein both in parathyroid glands and in renal tubules (5). Serum magnesium is typically found in the higher range of normal values or modestly elevated $(5,6)$.

Parathyroid cells respond to the decrease in extracellular calcium concentration through activation of the CASR gene, a cell surface seven-membranespanning $\mathrm{G}$ protein-coupled receptor, modulating phosphatidylinositol turnover and intracellular calcium amount that ultimately leads to an increase in the secretion of PTH (7). CASR is able to sense small changes in circulating calcium concentration and when activated inhibits PTH secretion and renal tubule calcium reabsorption. The 'set-point' of parathyroid cells, defined as that calcium concentration at which PTH secretion is half maximal, is increased in FHH patients. Renal calcium handling is also abnormal in 
FHH individuals and even if the magnitude of the PTH suppression by increased serum calcium concentrations is normal, they generally fail in the hypercalciuric response to hypercalcemia (5). In fact, the tubular reabsorption of calcium in FHH is high and remains increased even after an intended or unintended total parathyroidectomy.

Most FHH patients are identified by chance and the recognition of mild hypercalcemia in first-degree relatives supports the diagnosis. Easy fatigue, weakness, thought disturbance, or polydipsia is generally less common and less severe than in typical PHPT (7). The clinical complications observed in $\mathrm{FHH}$ patients mainly consist of chondrocalcinosis (usually clinically silent), premature vascular calcification $(8$, 9), and pancreatitis (10). However, acute pancreatitis and gallstones have also been reported in isolated cases (11).

Unfortunately, despite what has been just described, most asymptomatic FHH subjects are still misdiagnosed as affected by sporadic PHPT and addressed to undergo neck surgery, exposing them to the potentially related life-threatening risks. In the 1980s it has been estimated that in the USA about 25 patients with FHH received unsuccessful parathyroidectomy each year, with their hypercalcemic relatives not being recognized or informed of the nature of their disorder (10). This is still true in Italy.

We have had the opportunity to investigate an Italian FHH family (FHH-01) through the identification of a young male proband who was addressed to our outpatient service for a detailed clinical endocrine-metabolic screening before an already planned parathyroidectomy. An extended follow-up is reported here.

\section{Materials and methods}

\section{Family members}

The proband was a 32-year-old male diagnosed as affected by PHPT by an outside outpatient clinic and parathyroidectomy was already planned for him. He was referred to our center to receive an adequate metabolic and clinical assessment before neck surgery. The previous biochemical findings (Table 1), leading to the initial diagnosis of PHPT, consisted of a moderate hypercalcemia $(10.8 \mathrm{mg} / \mathrm{dl})$ in the presence of a slightly increased serum PTH $(7.7 \mathrm{pmol} / \mathrm{l})$. However, the young age of the subject prompted us to investigate the possibility of FHH.

The pattern of biochemical investigations routinely used confirmed the suspicion of hypocalciuric hypercalcemia (Table 1). An accurate clinical familial history was completed and the pedigree (FHH-01) was drawn (Fig. 1), and after having obtained informed consent, as formulated by the Local Ethics Committee of the University of Florence, a mutation analysis of the CASR gene was performed in the II-2 proband.

After genetic counseling, the other members from the family (father (I-1), mother (I-2), sister (II-1), and brother (II-3; Fig. 1)) underwent DNA tests. All subjects except I-1 accepted to be clinically screened for calcium phosphate metabolism (Table 1).

\section{DNA testing}

Blood-EDTA samples were collected from I-1, I-2, II-1, II-2, and II-3 to search for the CASR gene germline mutation detected in II-2. CASR mutational analysis was also performed on 120 normal individuals (60 males and 60 females) whose ages ranged from 50 to 85 years.

Table 1 Biochemical features of members from the family $\mathrm{FHH}-01$. The $\mathrm{u}-\mathrm{Ca} / \mathrm{Cr}$.Cl. ratio has been calculated according to the well-known formula: $\mathrm{CaCl} . / \mathrm{Cr} . \mathrm{Cl} .=(\mathrm{u}-\mathrm{Ca} \times \mathrm{V} / \mathrm{s}-\mathrm{Ca}) /(\mathrm{u}-\mathrm{Cr} . \times \mathrm{V} / \mathrm{s}-\mathrm{Cr})=.(\mathrm{u}-\mathrm{Ca} \times \mathrm{s}-\mathrm{Cr}) /.(\mathrm{u}-\mathrm{Cr} . \times \mathrm{s}-\mathrm{Ca})$.

\begin{tabular}{lcccc}
\hline Referring range & $\begin{array}{c}\text { Il-2 } \\
\text { mean } \pm \text { s.D. }\end{array}$ & $\begin{array}{c}\text { I-2 } \\
\text { mean } \pm \text { s.D. }\end{array}$ & II-1 & $\begin{array}{c}\text { II-3 } \\
\text { mean } \pm \text { s.D. }\end{array}$ \\
\hline s-Ca (mg/dl; 8.2-10.7) & $10.8 \pm 0.4$ & $10.6 \pm 0.2$ & 9.2 & $10.5 \pm 0.1$ \\
u-Ca (mg/24 h; 100-300) & $146.4 \pm 26.4$ & $52.8 \pm 32.2$ & 152 & $131 \pm 29.7$ \\
s-P (mg/dl; 2.5-5.0) & $33.5 \pm 0.3$ & $2.8 \pm 0.2$ & 3.0 & $2.1 \pm 0.1$ \\
u-P (mg/24 h; 400-1000) & $924.4 \pm 195.3$ & $745.2 \pm 100.8$ & 432 & $999.0 \pm 69.3$ \\
s-Mg (mg/dl; 1.8-2.6) & $2.5 \pm 0.1$ & $2.4 \pm 0.4$ & 2.0 & $2.4 \pm 0.2$ \\
u-Mg (mg/24 h; 75-125) & $76.7 \pm 7.3$ & $78.2 \pm 12.3$ & 40 & $42.5 \pm 6.4$ \\
s-Cr. (mg/dl; 0.6-1.5) & $0.9 \pm 0.1$ & $0.9 \pm 0.1$ & 1.0 & $0.9 \pm 0.0$ \\
u-Cr. (g/24 h; 0.8-1.8) & $1.8 \pm 0.3$ & $1.0 \pm 0.1$ & 0.9 & $0.9 \pm 0.1$ \\
Cr.Cl. (ml/min; 70-140) & $151.5 \pm 16.5$ & $114.4 \pm 24.0$ & 130 & $138 \pm 2.8$ \\
s-Total proteins (g/dl; 6.0-8.6) & $7.1 \pm 0.1$ & $7.1 \pm 0.2$ & 7.0 & $7.2 \pm 0.1$ \\
s-PTH (pmol//; 1.3-7.6) & $7.2 \pm 1.1$ & $6.1 \pm 1.7$ & 5.2 & $6.7 \pm 0.2$ \\
bAP (U//; 10-25) & $20.8 \pm 7.3$ & $23.4 \pm 8.0$ & 28 & $19.5 \pm 0.7$ \\
s-25OHD (ng/ml; $\geq 30)$ & $32.9 \pm 10.2$ & $41.1 \pm 19.1$ & 42 & $34.5 \pm 2.1$ \\
i-Ca (mmol//; 1.15-1.30) & $1.3 \pm 0.1$ & $1.3 \pm 0.1$ & 1.1 & $1.3 \pm 0.0$ \\
Pyridinoline (nmol/nmol Cr.; 2.3-5.4) & $4.4 \pm 1.0$ & $6.0 \pm 2.1$ & 2.8 & $6.5 \pm 0.3$ \\
CaCl./Cr.Cl. & $<0.001$ & $<0.001$ & 0.01 & $<0.001$ \\
\hline
\end{tabular}

Ca, calcium; P, phosphate; Mg, magnesium; s, serum; u, urine; bAP, bone alkaline phosphatase; i, ionized; Cr., creatinine; Cl., clearance. 


\section{Family FHH-01}

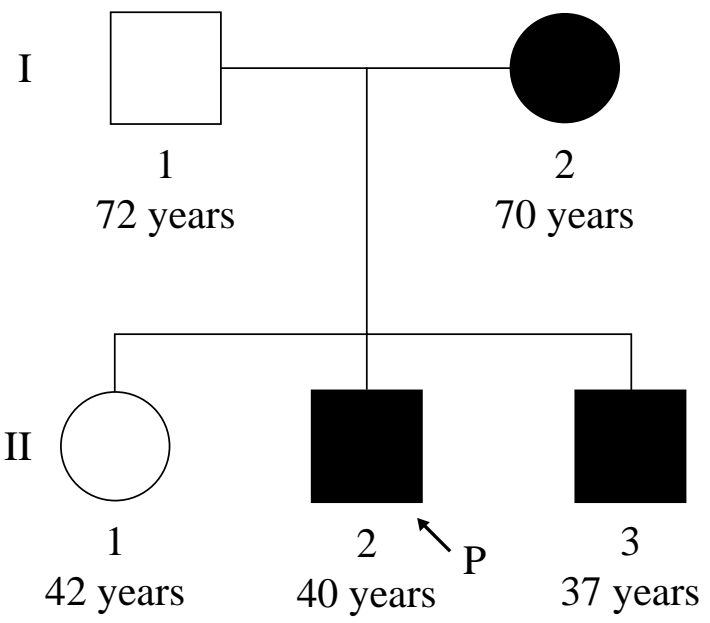

Figure 1 The pedigree of $\mathrm{FHH}-01$ is depicted. On the left side, Roman numbers I and II indicate the generation. Black symbols (squares and circles) indicate subjects carrying heterozygous mutation in CASR gene. Open square and open circle represents non-mutant subjects, Letter $\mathrm{P}$ and the arrow indicate the proband. Under each subject, the corresponding current age is reported.

Genomic DNA was extracted from peripheral whole blood using the QIAamp DNA Blood Mini Kit according to the manufacturer's instructions (Qiagen).

Each of the six coding exons (exons 2-7) and part of the flanking introns of the CASR gene were amplified in separate tubes by PCR using appropriate primer sets (available upon request; MWG-Biotech, Ebersberg, Germany). PCR reactions were performed in a Bio-Rad iCycler system thermocycler (Bio-Rad) according to an already described protocol (12) and the products were visualized by electrophoresis on a standard $2 \%$ agarose gel stained with ethidium bromide. PCR amplicon purification, cycle sequencing, sequencing products purification, and sequencing analysis were performed according to the literature (12). The obtained forward and reverse DNA sequences were compared with the genomic reference sequence of CASR gene published on the NCBI database (sequence accession number and version: NC_000003.11).

Following identification of the heterozygous causative mutation in exon 3, amplification of exon 3 from the genomic DNA was repeated. The Taq polymeraseamplified PCR products were directly cloned into the blue/white selection vector pCRII using TA Cloning Kit Dual Promoter (Invitrogen Corp., Carlsbad, CA, USA) according to the manufacturer's instructions. TaKaRa Escherichia coli DH5 $\alpha$ Competent Cells (Takara Bio, Inc., Otsu, Shiga, Japan) was used as host strain. Positive clones containing the wild-type or mutated allele were screened by means of PCR from bacterial white colonies and then sequenced. Amplified exon 3 from different bacterial clones (wild-type and deleted) were mixed in similar concentrations and then denatured and renatured $\left(7 \mathrm{~min}\right.$ at $94{ }^{\circ} \mathrm{C}$ and $15 \mathrm{~min}$ at $\left.42{ }^{\circ} \mathrm{C}\right)$ to be visualized by agarose gel electrophoresis.

\section{Biochemical investigations}

Patients I-2, II-2, and II-3 did accept to undergo biochemical screening at our center. Subject II-1, nonmutant, accepted to undergo the baseline tests in 2006.

In particular, subject I-2 has been screened from 2002 through 2010; II-2, the proband, from 1999 to 2001 in external laboratories and from 2002 through 2010 at our center; and II-3 from 2005 through 2006 (Table 1). The results of the biochemical screening performed in all individuals are reported in Table 1.

\section{Instrumental investigations}

Subjects I-2 and II-2 underwent bone mass evaluation (bone mineral density (BMD)) by Dual X-ray absorptiometry (DXA) scans (Hologic QDR-4500A, Waltham, MA, USA): I-2 at left femur (LF) in 2002 and LF and lumbar spine (LS) in 2008; II-2 at LS and LF in 2005 and 2008. I-2 has also been investigated by total abdomen and right shoulder ultrasounds (US) to verify the clinical suspect of gall bladder stones and calcifications at the soft tissues of the right shoulder respectively.

Moreover, in patient I-2, the presence of a degenerative maculopathy with visual impairment has also been investigated by eye evolution and fluoroangiography. In January 2009, after performing LS and LF DXA scans, she underwent lumbar-sacral nuclear magnetic resonanace (NMR).

\section{Site-directed mutagenesis of the human CASR and transient receptor expression}

The human wild-type CASR cDNA, cloned in pCR3.1 plasmid (Invitrogen), was kindly provided by Dr Jianxin $\mathrm{Hu}$ (NIH, Bethesda, MD, USA).

In vitro site-directed mutagenesis was directly applied on wild-type CASR plasmid to construct a mutant receptor containing the four-nucleotide deletion (briefly referred to as $\Delta 121$ ) using the Gene Tailor Site-Directed Mutagenesis System (Invitrogen). The deletion was produced by PCR amplification using two overlapping primers, only one containing the target mutation site (forward mutagenic primer: TGCTCAAAACAAAATT/CTTTGAACCTTGATGAC; reverse primer: ATTTTGTTTTGAGCAACAAAACTTCAGGGTGG). The Platinum Taq DNA Polymerase High Fidelity (Invitrogen) was used for 20 amplification cycles. Mutant plasmids were amplified in E. coli, DH-5 $\alpha$ strain, and DNA was extracted with the alkaline lysis procedure.

Mutation was confirmed by automated DNA sequencing of entire CASR cDNA using ABI PRISM 3100 Genetic Analyzer with the Big-Dye Terminator V1.1 Kit (Applied Biosystem, Foster City, CA, USA). 
Human embryonic kidney cells (HEK-293; Cell Bank, IST, Genoa, Italy) were grown in DMEM medium (Sigma Chemicals), supplemented with $10 \%$ FBS and 1\% penicillin/streptomycin (Euroclone, Devon, UK). Transfection was performed using $10 \mu \mathrm{g}$ plasmid DNA for each transfection in a $25 \mathrm{~cm}^{2}$ flask of HEK-293 cells. DNA was diluted in OptiMEM (Invitrogen); Lipofectamine (Invitrogen) was incubated with OptiMEM for 5 min at room temperature. Then, DNA was gently mixed with Lipofectamine and the mixture was incubated at room temperature for $30 \mathrm{~min}$. The DNALipofectamine complex was further diluted in OptiMEM and was added to $80 \%$ confluent HEK-293 cells plated in $25 \mathrm{~cm}^{2}$ flasks. After $5-6 \mathrm{~h}$ of incubation, $2.5 \mathrm{ml}$ complete DMEM was added. The medium was refreshed $24 \mathrm{~h}$ after transfection. Cotransfection of wild-type and mutant receptor was carried out as described before with $5 \mu \mathrm{g}$ of each plasmid. The expressed CASR protein was assayed $48 \mathrm{~h}$ after the initiation of transient transfection on immunoblots stained with anti-CASR $\mathrm{MAB}$ to detect total immunoreactive species.

\section{Western blotting}

Transiently transfected cells were lysed with $0.1 \mathrm{M}$ $\mathrm{NaOH}$ and scraped from flasks. The viscose solution was passed through a needle of a syringe and transferred into microcentrifuge tubes. Proteins were dissolved in Laemmli sample buffer (final concentration 3\% SDS and $2 \%$ mercaptoethanol). Samples (150 mg proteins/well) were separated on Laemmli gel (acrylamide gradient 7-15\%) and electrophoretically transferred on PVDF membrane. The blots were blocked in a blocking solution (5\% milk in PBS) and then incubated overnight at $4{ }^{\circ} \mathrm{C}$ with primary rabbit anti-CASR polyclonal antibody, PA1-934, diluted 1:500 in the blocking solution (Affinity Bioreagents, Golden, CO, USA). The same membranes were incubated with polyclonal antiactin antibody (Sigma Chemicals) overnight at $4{ }^{\circ} \mathrm{C}$ with a 1:1000 dilution. Both blots were incubated for $1 \mathrm{~h}$ at room temperature in HRP-conjugated goat antirabbit secondary antibodies diluted 1:2000. The specific protein bands were detected using an enhanced chemiluminescence system.

\section{Measurement of $\left[\mathrm{Ca}^{2+}\right]_{i}$}

Transfected HEK-293 cells were trypsinized and counted for each experiment. About $5 \times 10^{5}$ cells $/ \mathrm{ml}$ were used. The samples were loaded with Fura-2 AM (Sigma Chemicals; $1 \mu \mathrm{M}$ final concentration, $37^{\circ} \mathrm{C}$, $45 \mathrm{~min})$ in a bath solution $(123 \mathrm{mM} \mathrm{NaCl}, 5 \mathrm{mM} \mathrm{KCl}$, $1 \mathrm{mM} \mathrm{MgCl}, 10 \mathrm{mM}$ glucose, $25 \mathrm{mM}$ HEPES, $0.5 \mathrm{mM}$ $\mathrm{CaCl}_{2}$, pH 7.4 at $37^{\circ} \mathrm{C}$, and $285 \mathrm{mosm} / \mathrm{l}$ ). At the end of incubation, cells were washed using the bath solution and transferred into a thermostated quartz cuvette containing the bath solution. Extracellular calcium concentration $\left[\mathrm{Ca}^{2+}\right]_{\mathrm{o}}$ was increased stepwise by $1 \mathrm{mM}$ (from 0.5 to $12 \mathrm{mM}$ ). The fluorescence measurements were carried out with the luminescence spectrometer LS 50B (Perkin-Elmer, Norwalk, CT, USA) at $37^{\circ} \mathrm{C}$ under magnetic stirring and were recorded at 340 and $380 \mathrm{~nm}$ excitation light with $510 \mathrm{~nm}$ emission. The data were analyzed by WinLab Software package (Perkin-Elmer) that allows for a fluorescence lecture every $1.9 \mathrm{~s}$. The intracellular calcium concentration $\left[\mathrm{Ca}^{2+}\right]_{\mathrm{i}}$ was calculated from fluorescence ratio (340/380 excitation) as described previously $(13,14)$.

\section{Statistical analysis}

The mean $\mathrm{EC}_{50}$, which is extracellular calcium concentration giving half maximal response, for wildtype and mutant receptor was calculated from all individual experiments $(n=4)$ and expressed as s.E.M. of the mean. The $\mathrm{EC}_{50}$ values were compared using Mann-Whitney $U$ test.

\section{Results}

\section{DNA analysis}

After comparison with the wild-type genomic CASR sequence, a novel germline heterozygous 4 bp deletion of nucleotides 361-364 (GATT) in exon 3 (coding DNA reference sequence on NCBI database NM_000388.3:c.361_364delGATT or c.361_364del4; protein reference sequence on NCBI database NP_000379.2:p.Asp121fs or p.Asp121LeufsX) was detected in I-2, II-2, and II-3 subjects (Fig. 1). The mutation was inherited by I-2, with I-1 exhibiting wild-type sequence. The deletion of a nonmultiple of three nucleotide bases changed the reading frame for the entire subsequent sequence, impairing the function of the resulting protein, if it is formed. Indeed, the mutation causes a frameshift after Ile120 that results in a UGA (opal) termination codon, two codons downstream of the mutation site (Fig. 2A). The sequence change has been confirmed by sequencing both strands of DNA from two different PCR products. This deletion introducing a premature stop codon in the gene sequence causes a loss-of-function mutation, deleting all the functional parts of the protein and it has not been previously described (http://www.casrdb.mcgill.ca). This sequence variation could not be found in a sample of 120 normal chromosomes.

The presence of the wild-type allele in the homozygous state was indicated by a single PCR product of $364 \mathrm{bp}$. Instead, an abnormal pattern of migration of the PCR-amplified products containing exon 3 was detected for each heterozygous member of the family (Fig. 2B). In fact, two bands appeared after separation by electrophoresis on a standard $2 \%$ agarose gel stained with ethidium bromide due to homoduplex and heteroduplex formation between the long and short 
alleles, which were 364 and 360 bp respectively. Annealing of mutated to wild-type DNA alleles gives duplexes with one or more mismatched (heteroduplexes) running slower than homoduplexes. Base mismatching causes the double helix to take on a conformation that retards its mobility during electrophoresis.

Moreover, the sequence data obtained when CASR exon 3 PCR products from the proband were individually cloned in pCR II vectors and sequenced using M13 forward primer more clearly revealed the presence of the
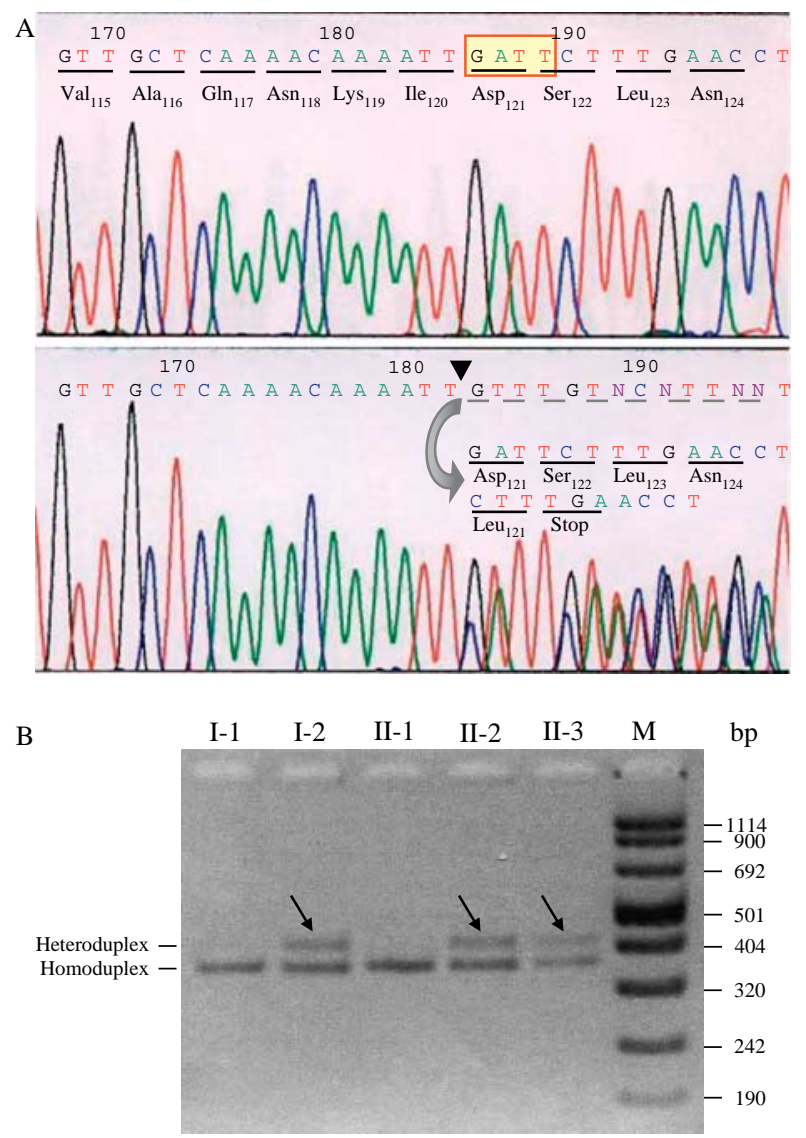

$\mathrm{C}$

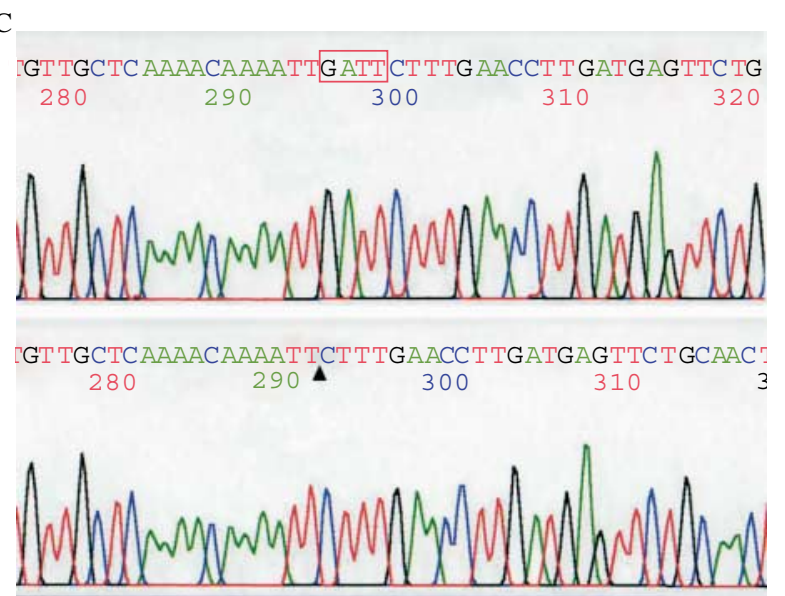

wild-type and mutated alleles, the latest with a deletion of four bases ( $5^{\prime}$-GATT-3'; Fig. 2C). The sequence data of clones were in agreement with those obtained by direct sequencing of the PCR products from heterozygous individuals.

After a denaturation/renaturation step, the mixture of exon 3 PCR products separately amplified from wildtype and mutated alleles was electrophoresed on ethidium bromide-stained agarose gel. Homoduplexes and heteroduplexes were detected with the same electrophoretic migration pattern observed for PCR products from heterozygous individuals.

\section{Biochemical/clinical investigations}

The results of biochemical screening and corresponding normal range values are detailed in Table 1 . The results are expressed as mean values \pm s.D. of measurements made in the years outlined earlier, but for patient II-1 who had only one evaluation.

I-2 She also suffered from arterial hypertension and esophageal hiatus hernia. Moreover, she was mildly hypercalcemic, with PTH values in the upper part of the normal range and inappropriate low urinary calcium excretion levels. Her $\mathrm{u}-\mathrm{Ca} / \mathrm{Cr}$. clearance ratio was $<0.001$ (Table 1).

II-1 She was found to be normocalcemic, with normal PTH levels and normal urinary calcium excretion. Her $\mathrm{u}-\mathrm{Ca} / \mathrm{Cr}$. clearance ratio was $>0.01 \mathrm{ng} / \mathrm{ml}$ (Table 1 ).

II-2 (proband) He was originally diagnosed as affected by sporadic PHPT due to the presence of hypercalcemia, with slightly increased PTH levels, inappropriate urinary calcium excretion levels, and $\mathrm{u}-\mathrm{Ca} / \mathrm{Cr}$. clearance

Figure 2 (A) Portions of DNA sequence electropherograms of CASR exon 3 obtained from normal subject I-1 (upper panel) and proband II-2 (lower panel). The nucleotide sequences are depicted from $5^{\prime}$ to $3^{\prime}$ starting with the nucleotide c343. Patient II-2 shows overlapping peaks after nucleotide 360 of the cDNA due to heterozygous 4 bp deletion at nucleotides 361-364. The black arrow shows the position of the mutation. The GATT-deleted nucleotides are boxed in solid red line in the wild-type sequence of normal subject I-1. The deletion causes a frameshift creating a termination codon (stop) at position 122. Translated amino acids are numbered and shown underneath the nucleotide sequences. (B) Standard $2 \%$ agarose gel stained with ethidium bromide used to visualize the PCR products containing exon 3 from each members of the family FHH-01. Lanes 1 and 3 (for I- 1 and II-1 subjects respectively) show the amplification product of homozygous normal individuals as a single band of $364 \mathrm{bp}$; lanes 2 , 4, and 5 (for I-2, II-2, and II-3 subjects respectively) show the amplification products obtained from heterozygous subjects with two different bands, a more rapidly migrating band for homoduplexes and a slower running band for heteroduplexes (indicated by black arrows); lane 5 (M) denotes DNA Molecular Weight Marker VIII (Roche Applied Science). (C) Sequences of wild-type and mutated allele (upper and lower panels respectively) for the individually cloned PCR products of exon 3 obtained from proband II-2. The black triangle shows the position of deleted GATT nucleotides boxed in solid red line. 
ratio $<0.001$ (Table 1 ). His pituitary/gonadal axis evaluation (FSH, LH, and serum total testosterone) did not show any abnormality (data not shown).

II-3 He was found to be normocalcemic with PTH levels in the upper part of the normal range, inappropriate urinary calcium excretion levels, and $\mathrm{u}-\mathrm{Ca} / \mathrm{Cr}$. clearance ratio $<0.001$ (Table 1 ).

All the mutant subjects (I-2, II-2, and II-3) also exhibited serum magnesium values in the upper part of the normal range, while the average of their 25-hydroxyvitamin D circulating levels was adequate.

\section{Instrumental investigations}

I-2 Bone mineral density. She was osteopenic at LF neck, $0.604 \mathrm{~g} / \mathrm{cm}^{2}$ (T-score: -2.21 s.D.) in 2002, whereas in 2008, the LF neck BMD became osteoporotic, $0.641 \mathrm{~g} / \mathrm{cm}^{2}$ (T-score: -2.8 s.D.). A clear osteoporotic result has also been observed at LS level in 2008 (not performed in 2002): L2-L4, $0.690 \mathrm{~g} / \mathrm{cm}^{2}$ (T-score -4.3 S.D.).

Lumbar-sacral NMR. A lumbar right convex scoliosis, stress fracture at S1 vertebral body, and multiple discs dehydration were reported.

Total abdomen US. The presence of a mobile small ( $8 \mathrm{~mm})$ gall bladder stone and cholecystitis and an angiolipoma of the left kidney was reported.

Right shoulder US. Presence of degenerative aspects in this joint and the surrounding structures with some fine microcalcifications of soft tissues was reported. The final diagnosis was of a second-degree subacromial conflict syndrome.

Eyes visit and fluoroangiography. Both second-degree hypertensive retinopathy and hyperfluorescence at the interpapillo-macular level have been diagnosed in the left eye.

II-2 Bone mineral density. In 2001, he exhibited a slight osteopenia at LS (L2-L4), $0.969 \mathrm{~g} / \mathrm{cm}^{2}$ (T-score -1.32 S.D.), and a normal LF neck BMD, $0.879 \mathrm{~g} / \mathrm{cm}^{2}$ (T-score - 0.37 s.D.). Then, in 2005, LS BMD was $1.027 \mathrm{~g} / \mathrm{cm}^{2}$ (T-score -1.4 s.D.) and LF neck BMD scored $0.924 \mathrm{~g} / \mathrm{cm}^{2}$ (T-score 0.0 s.D.). Finally, in 2008, a decreased, osteopenic BMD at LS level was observed, $1.012 \mathrm{~g} / \mathrm{cm}^{2}$ (T-score -1.9 S.D.), whereas a stable condition of normality was still reported at LF neck, $1.029 \mathrm{~g} / \mathrm{cm}^{2}$ (T-score -0.3 S.D.).

\section{Site-directed mutagenesis and transient receptor expression}

The sequencing showed a shorter CASR molecule (fournucleotide deletion) and no other mutations were produced.
We compared the receptor expression at protein level in the wild type (WT)-CASR-transfected cells with that in the $\Delta 121-C A S R$-transfected and WT/ $\Delta 121$ cotransfected cells. Antibody detected a $\sim 140 \mathrm{kDa}$ band for both WT-CASR-transfected and WT/D121 cotransfected cells (with no appreciable differences of expression), while no expression was detected for $\Delta$ 121-CASR-transfected cells (Fig. 3A).

\section{Functional characterization of $\triangle 121$-CASR using the intact cell $\left[\mathrm{Ca}^{2+}\right]_{o}$ : stimulated assay}

Measurements of $\left[\mathrm{Ca}^{2+}\right]_{\mathrm{i}}$ responses in HEK-293 cells transfected with the WT receptor showed an $\mathrm{EC}_{50}$ for

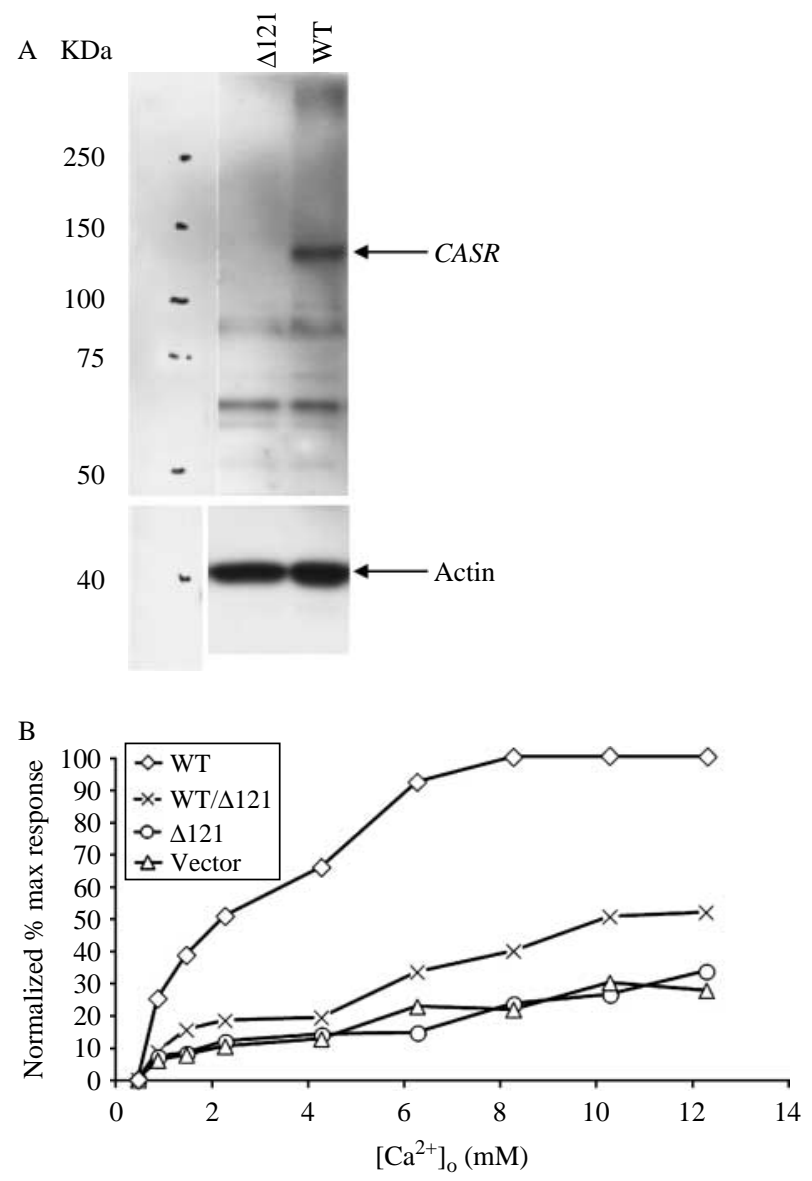

Figure 3 (A) Western blot from transfected HEK-293 cells immunostained with anti-CASR rabbit polyclonal antibody, generated against a synthetic peptide corresponding to amino acid residues 1227 of the CASR. Cells transfected with the WT-CASR cDNA express an immunostainable band at $\sim 140 \mathrm{kDa}$, which is not detectable in the cells transfected with B121. Actin control staining was performed. (B) Fluorescence responses of CASR-transfected HEK-293 cells to increasing levels of $\left[\mathrm{Ca}^{2+}\right]_{0}$. All responses were normalized to the maximum response of the wild-type receptor. Each data point is the mean value of four measurements. The $\mathrm{EC}_{50}$ for the WT receptor was significantly different from that of the WT/B121 CASR $(P=0.02)$. The B121 mutant had no response to $12 \mathrm{mM}$ extracellular calcium as the cells transfected with empty vector. 
$\left[\mathrm{Ca}^{2+}\right]_{\mathrm{o}}$ of $3.6 \pm 0.3 \mathrm{mM}(n=4)$. Figure $3 \mathrm{~B}$ shows that HEK-293 transfected with empty vector had no calcium response. The $\Delta 121$ mutant also had no calcium response with $12 \mathrm{mM}\left[\mathrm{Ca}^{2+}\right]_{\mathrm{o}}$.

HEK-293 cotransfected with equal amounts of WT and $\Delta 121$ mutant CASR cDNA showed a sensitivity to $\left[\mathrm{Ca}^{2+}\right]_{0}$ intermediate between that of cells transfected with mutant or the WT cDNA alone, with an $\mathrm{EC}_{50}$ of $10.5 \pm 0.6 \mathrm{mM}$ for $\left[\mathrm{Ca}^{2+}\right]_{\mathrm{o}}(n=4 ; P=0.02$ vs HEK-293 cells transfected with the WT receptor; Mann-Whitney $U$ test; Fig. 3B).

\section{Discussion}

Inactivating mutations in the human CASR gene cause both FHH and its homozygous form, the neonatal severe hyperparathyroidism (NSHPT) (15). In FHH and NSHPT subjects, probably mutations in the amino acid coding region are detected in more than 99\% of cases.

We found a novel germline heterozygous frameshift mutation at codon 121 in a hypercalcemic subject and his family members. Asp121 is located in the extracellular calcium-binding domain of the receptor, phylogenetically well conserved through many species. This frameshift mutation caused a premature stop codon at codon 122, exiting a truncated protein, completely disrupting the function of the resulting protein and likely to be pathogenic. Its presence, in the heterozygous state, was detectable by agarose gel electrophoresis as heteroduplex artifact, because the deletion of $4 \mathrm{bp}$ from one allele in the heterozygotes creates PCR artifact products with an aberrant migration, as heteroduplexes with mismatches migrate more slowly than homoduplexes.

The biochemical phenotype of the mutated family members was concordant with the classical expression reported in $\mathrm{FHH}$ patients. In particular, all of them had a calcium clearance/creatinine clearance ratio $<0.001$ whereas nonmutant II-1 exhibited a ratio $>0.01$.

An inappropriately lower $24 \mathrm{~h}$ urinary calcium excretion was observed in subject I-2 when compared with subjects II-2 and II-3. As the coexistence of mutated and normal CASR in parathyroid tissue and in renal tubular cells is supposed to exist in all heterozygous subjects, it may not provide an alternative explanation for the absence of a clear hypocalciuria in II-2 and II-3 with respect to I-2. Consequently, other unidentified genetic (e.g. modifying genes) and/or nongenetic factors (e.g. diet, physical activity, and age) could account for such a difference.

Average serum PTH levels were within the normal range in all the mutants, even if subject II-2, with higher average values of serum calcium, showed PTH values higher than the upper normal range.

Adequate daily supplementation of cholecalciferol, 750-1000 IU, has been provided to all the subjects when needed. The average levels of bAP were within the referring range in all heterozygous subjects.

I-2 and II-2 mutants, but not II-3, accepted to perform BMD evaluation. Subject I-2 was osteoporotic whereas subject II-2 showed a mild osteopenia, despite his young age and the fact that he has been performing daily regular physical activity. Osteoporosis has been reported in some FHH families (16), although it seems to be an unusual feature of the disorder. In fact, FHH has been associated with increased PTH and AP levels when compared with normal controls, but not with bone loss irrespective of the severity of the CASR mutations (17).

The overall clinical features reported in the postmenopausal mother (I-2) correlated with a compromised quality of life (osteoporosis, lumbar right convex scoliosis, stress fracture of S1 vertebral body, multiple discs dehydration, gall bladder stone, cholecystitis, left kidney angiomyolipoma, hypertension, and hypertensive retinopathy). All these features cannot be directly correlated with $\mathrm{FHH}$, even if disorders such as gallstones have been reported in isolated cases (11).

In fact, even if it has been reported that marked differences in plasma calcium and PTH levels may depend on the CASR gene mutation, an accurate collection of a familial and personal history of the patients together with an accurate physical examination would make possible the recognition of clinical phenotypes segregating with the CASR gene mutations. Indeed, in $\mathrm{FHH}$ patients, the need for a very detailed clinical data collection is urgently felt. This would make possible in the future to describe clinical entities, possibly associated with this disease, such as psychotic symptoms (18).

Our findings support the role of CASR DNA test as a valuable supplement to the clinical diagnosis of $\mathrm{FHH}$ in hypercalcemic patients. Today, CASR genetic test may be used for diagnostic testing in the symptomatic individual (proband) and in presymptomatic subjects (19). The problem is still how to suspect the FHH syndrome. Certainly, a positive family history of hypercalcemia is still the most relevant predictive factor for CASR gene mutations (12), whereas clinical and biochemical parameters do not reliably distinguish between PHPT and FHH (20). However, familial hypercalcemia is not often reported in the history of the patients, mostly if asymptomatic. One reason to suspect a hereditary hyperparathyroid syndrome is certainly the young age of the subject, as it happened in this case.

The possibility to avoid any unuseful parathyroid surgery is very important because cinacalcet can today show efficacy in patients with hypercalcemia due to inactivating mutations of the CASR $(18,21,22)$.

In conclusion, FHH syndrome should be suspected when a young subject is diagnosed with PHPT without any family history of this syndrome. The possibility to use CASR genetic screening is certainly recommended when no PHPT syndromic disorders are suspected and 
other asymptomatic or paucisymptomatic hypercalcemic subjects are recognized in the family. In the future, common shared clinical protocols could make possible the recognition of clinical signs or symptoms, beside hypercalcemia, recognizable as typical of $\mathrm{FHH}$.

\section{Declaration of interest}

The authors declare that there is no conflict of interest that could be perceived as prejudicing the impartiality of the research reported.

\section{Funding}

This paper was supported by an unrestricted grant from F. I. R. M. O. Fondazione Raffaella Becagli (to M L Brandi). The research was supported by grants from the Italian Ministry of University and Research (attributed to L Soldati: FIRST and Cofin 02) and from San Raffaele Hospital.

\section{Acknowledgements}

We thank Dr Sergio Salardi, Prassis Research Institute, Milan, for his help with the western blot analysis; Dr Marie Louise Syren, Pediatric Institute, University of Milan, for DNA sequencing; and Drs J Hu and M Spiegel for providing us with the original human CASR plasmid. Identification of novel germline inactivating mutation of CASR and its functional analysis are reported. DNA test was helpful to avoid useless neck surgery.

\section{References}

1 Pollak MR, Brown EM, Chou YH, Hebert SC, Marx SJ, Steinmann B, Levi T, Seidman CE \& Seidman JG. Mutations in the human $\mathrm{Ca}(2+)$-sensing receptor gene cause familial hypocalciuric hypercalcemia and neonatal severe hyperparathyroidism. Cell $1993 \mathbf{7 5}$ 1297-1303. (doi:10.1016/0092-8674(93)90617-Y)

2 Marx SJ, Spiegel AM, Brown EM \& Aurbach GD. Family studies in patients with primary parathyroid hyperplasia. American Journal of Medicine 197762 698-706. (doi:10.1016/00029343(77)90873-7)

3 Thorgeirsson U, Costa J \& Marx SJ. The parathyroid glands in familial hypocalciuric hypercalcemia. Human Pathology 198112 229-237. (doi:10.1016/S0046-8177(81)80123-2)

4 Marx SJ, Stock JL, Attie MF, Downs RW Jr, Gardner DG, Brown EM, Spiegel AM, Doppman JL \& Brennan MF. Familial hypocalciuric hypercalcemia: recognition among patients referred after unsuccessful parathyroid exploration. Annals of Internal Medicine 1980 92 351-356.

5 Marx SJ, Attie MF, Levine MA, Spiegel AM, Downs RW Jr \& Lasker RD. The hypocalciuric or benign variant of familial hypercalcemia: clinical and biochemical features in fifteen kindreds. Medicine 198160 397-412. (doi:10.1097/00005792198111000-00002)

6 Kristiansen JH, Rodbro P, Christiansen C, Brochner Mortensen J \& Carl J. Familial hypocalciuric hypercalcaemia. II. Intestinal calcium absorption and vitamin D metabolism. Clinical Endocrinology 1985 23 511-515. (doi:10.1111/j.1365-2265.1985.tb01110.x)

7 Arnold A \& Marx SJ. Familial hyperparathyroidism (including MEN, FHH, and HPT-JT). In Primer on the Metabolic Bone Diseases and Disorders of Mineral Metabolism, 7th Edition ch 76, pp 361367. American Society for Bone and Mineral Research, 2009

8 Heath H III. Familial benign (hypocalciuric) hypercalcemia. A troublesome mimic of mild primary hyperparathyroidism. Endocrinology and Metabolism Clinics of North America 198818 723-740.
9 Volpe A, Guerriero A, Marchetta A, Caramaschi P \& Furlani L. Familial hypocalciuric hypercalcemia revealed by chondrocalcinosis. Joint, Bone, Spine 200976 708-710. (doi:10.1016/j.jbspin. 2009.02.001)

10 Marx SJ. Familial hypocalciuric hypercalcemia. New England Journal of Medicine 1980303 810-811. (doi:10.1056/NEJM198 010023031409)

11 Brown EM \& MacLeod RJ. Extracellular calcium sensing and extracellular calcium signaling. Physiological Reviews 200181 239-297.

12 Nissen PH, Christensen SE, Heickendorff L, Brixen K \& Mosekilde L. Molecular genetic analysis of the calcium sensing receptor gene in patients clinically suspected to have familial hypocalciuric hypercalcemia: phenotypic variation and mutation spectrum in a Danish population. Journal of Clinical Endocrinology and Metabolism 200792 4373-4379. (doi:10.1210/jc.2007-0322)

13 Soldati L, Spaventa R, Vezzoli G, Zerbi S, Adamo D, Caumo A, Rivera R \& Bianchi G. Characterization of voltage-dependent calcium influx in human erythrocytes by fura-2. Biochemical and Biophysical Research Communications 1997236 549-554. (doi:10. 1006/bbrc.1997.7002)

14 Soldati L, Adamo D, Zerbi S, Caumo A, Spaventa R, Bianchi G \& Vezzoli G. Erythrocyte voltage-dependent calcium influx is reduced in hemodialyzed patients. Kidney International 199956 190-197. (doi:10.1046/j.1523-1755.1999.00535.x)

15 Hendy GN, D’Souza-Li L, Yang B, Canaff L \& Cole DEC. Mutations of the calcium-sensing receptor (CASR) in familial hypocalciuric hypercalcemia, neonatal severe hyperparathyroidism, and autosomal dominant hypocalcemia. Human Mutation 2000 16 281-296. (doi:10.1002/1098-1004(200010)16:4<281:: AID-HUMU1 > 3.0.CO;2-A)

16 Abugassa S, Nordenstrom J \& Jarhult J. Bone mineral density in patients with familial hypocalciuric hypercalcaemia (FHH). European Journal of Surgery 1992158 397-402.

17 Christensen SE, Nissen PH, Vestergaard P, Heickendorff L, Rejnmark L, Brixen K \& Mosekilde L. Skeletal consequences of familial hypocalciuric hypercalcaemia versus primary hyperparathyroidism. Clinical Endocrinology $2009 \quad \mathbf{7 1}$ 798-807. (doi:10.1111/j.1365-2265.2009.03557.x)

18 Timmers HJ, Karperien M, Hamdy NA, de Boer H \& Hermus AR. Normalization of serum calcium by cinacalcet in a patient with hypercalcaemia due to a de novo inactivating mutation of the calcium-sensing receptor. Journal of Internal Medicine 2006260 177-182. (doi:10.1111/j.1365-2796.2006.01684.x)

19 Falchetti A, Marini F, Giusti F, Cavalli L, Cavalli T \& Brandi ML. DNA-based test: when and why to apply it to primary hyperparathyroidism clinical phenotypes. Journal of Internal Medicine 2009266 69-83. (doi:10.1111/j.1365-2796.2009. 02105.x)

20 Gunn IR \& Gaffney D. Clinical and laboratory features of calcium-sensing receptor disorders: a systematic review. Annals of Clinical Biochemistry 200441 441-458. (doi:10.1258/000 4563042466802)

21 Falchetti A, Cilotti A, Vaggelli L, Masi L, Amedei A, Cioppi F, Tonelli F \& Brandi ML. A patient with MEN1-associated hyperparathyroidism, responsive to cinacalcet. Nature Clinical Practice. Endocrinology \& Metabolism 20084 351-357. (doi:10. 1038/ncpendmet0816)

22 Marcocci C, Chanson P, Shoback D, Bilezikian J, Fernandez-Cruz L, Orgiazzi J, Henzen C, Cheng S, Sterling LR, Lu J \& Peacock M. Cinacalcet reduces serum calcium concentrations in patients with intractable primary hyperparathyroidism. Journal of Clinical Endocrinology and Metabolism 200994 2766-2772. (doi:10. 1210/jc.2008-2640)

Received 9 November 2011

Revised version received 3 February 2012

Accepted 7 February 2012 